\title{
A Study of Method Development, Validation and Forced Degradation for Quantification of Buprenorphine Hydrochloride in a Microemulsion Formulation
}

\author{
Dhanashree Arun Mundhey ${ }^{1 *}$, Vishal V. Rajkondawar ${ }^{1}$, Anwar S. Daud ${ }^{1}$, Nidhi P. Sapkal ${ }^{2}$ \\ ${ }^{1}$ Centre for Advanced Research \& Innovation (CARIn), Zim Laboratories Ltd. B-21/22, MIDC Area, Kalmeshwar 441501 Dist. Nagpur (M.S.), India., \\ ${ }^{2}$ Professor Pharmaceutical Chemistry, Gurunanak College of Pharmacy, Nari, Kamgarnagar, Nagpur (M.S.), India .
}

\author{
ARTICLE INFO \\ Article history: \\ Received on: 11/06/2016 \\ Revised on: 08/08/2016 \\ Accepted on: 18/09/2016 \\ Available online: 29/10/2016 \\ Key words: Buprenorphine \\ hydrochloride, High- \\ performance liquid \\ chromatography, \\ Microemulsion formulation, \\ forced degradation study.
}

\begin{abstract}
Objective: Development and validated of a simple, selective RP-HPLC method for the determination of buprenorphine hydrochloride in pharmaceutical microemulsion formulation. A forced degradation study of developed formulation was carried out in accordance with International Conference on Harmonization (ICH) guidelines Q1 (R2). Method: The chromatogram was obtained with $10 \mathrm{mmolL}^{-1}$ potassium phosphate buffer adjusted to $\mathrm{pH} 6.0$ with triethanolamine and acetonitrile (17:83, v/v) as mobile phase, C18 HPLC column $(250 \times$ $4.6 \mathrm{~mm}$ i.d., $5 \mu \mathrm{m}) \mathrm{kept}$ at $30^{\circ} \mathrm{C}$ and $\mathrm{UV}$ detection at $284 \mathrm{~nm}$. The compound was eluted isocratically at a flow rate of $1.0 \mathrm{~mL} \mathrm{~min}^{-1}$. Results: The average retention time for buprenorphine was $14.319 \mathrm{~min}$. The method was validated according to the ICH guidelines. The validation characteristics included accuracy, precision, linearity, range, specificity, limit of Quantitation and robustness. The calibration curves were linear $\left(\mathrm{R}^{2}>0.999\right)$ over the concentration range $1.0-500.0 \mu \mathrm{gmL}^{-1}$ for buprenorphine hydrochloride and recovery study for the compound was above $95 \%$. No spectral or chromatographic interferences from the microemulsion excipients were found. The drug was found to be labile under oxidative stress condition; whereas stable under all other stress conditions. Conclusion: This method is simple, rapid and suitable for routine quality control analysis.
\end{abstract}

\section{INTRODUCTION}

Buprenorphine hydrochloride (BU) is chemically known as (6R, 7R, 14S)-17cyclopropylmethyl- 7, 8-dihydro-7-[(1 S)-1-hydroxy-1, 2, 2 trimethylpropyl]-6-0-methyl-6, 14-ethano17-normorphine hydrochloride (USP, 2007; Drugbank, 2016; Sweetman, 2009; Ash et al., 1996). The molecular formula of BU is $\mathrm{C}_{29} \mathrm{H}_{41} \mathrm{NO}_{4}, \mathrm{HCl}$ and the molecular weight is 504.1 (Fig. 1). It is a potent semi-synthetic opiate analgesic with a potency of 20-40 times higher than that of morphine (Heel et al., 1979). As an analgesic, it is used successfully by intramuscular, intravenous and sublingual routes to treat moderate to severe pain as well as chronic pain (Hoskin et al., 1991). It is also indicated to treat opioid dependence by sublingual route (Dailymed, 2016).

* Corresponding Author

Email: dhanashree.mundhey@ zimlab.in
Literature survey reveals various analytical methods available for the quantitative determination of $\mathrm{BU}$, individually and in combination with other drugs.

BU in biological samples analyzed mainly using chromatographic methods such as gas chromatography with electron-capture detector (Everhart et al., 1997), HPLC with UV detector (Tebbett et al., 1985; Hackett et al., 1986); fluorescence detector (Liu et al., 2005; Garrett et al., 1985); electrochemical detector (Garcia-Fernandez et al., 2001) and some hyphenated techniques like HPLC-MS (Polettini et al., 1997; Moody et al., 2002; Pirnay et al., 2006; Rodriguez-Ross et al., 2007). But, as these methods reported for analysis of biological samples, these involve sample preparation steps consisting of extraction and/or derivatization before analysis. Thus, these methods are not suitable for analyzing BU in bulk drug or formulations. Mostafavi et al. reported a simultaneous estimation method for BU along with naloxone and noroxymorphine for tablet formulation using HPLC 
with UV detector at $210 \mathrm{~nm}$ (Mostafavi et al., 2009). But this method is suitable only for those formulations where no excipient absorbs at this wavelength range. To improve bioavailability of $\mathrm{BU}$, researchers formulate it into novel drug delivery systems like microemulsion, which contain excipients like oils, surfactants, cosurfactants etc. Many of these components are known to absorb in the $200-250 \mathrm{~nm}$ region of UV spectrum (Baboota et al., 2007; Wuelfing et al., 2006; Johnson, 2013). In this case method reported by Mostafavi et al. (2009) and Tebbett et al. (1985) is not suitable. Thus, there is a need to develop analytical method for quantitative estimation of $\mathrm{BU}$ in microemulsion formulation.

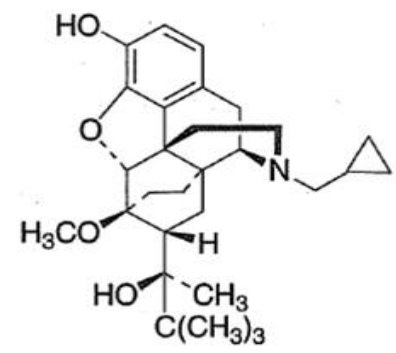

Fig.1: Chemical structure of Buprenorphine (BU).

The aim of the present study was to develop a simple, efficient, selective and validated RP-HPLC procedure for estimation of buprenorphine in ME formulation. The method requires no extraction or derivatization steps reducing additional chromatographic interferences and complexity of the method. The method validated according to the International Conference on Harmonization (ICH) guidelines Q2 (R1) (ICH, 2005).

According to the current ICH "Stability Testing Guidelines" Q1 A (R2), forced degradation studies of BU were also carried out (ICH, 2003) to give additional information of stability of BU during formulation, analysis and storage (Reynolds et al., 2002).

\section{MATERIALS AND METHODS}

BU-ME developed in the Centre for Advanced Research and Innovation (CARIn), Zim Laboratories, used for analytical method development. All other reagents were of HPLC grade obtained from Merk Specialties Pvt. Ltd. Water purified via a Milli-Q ${ }^{\circledR}$ Reference System, Millipore SAS (Molsheim, France) used for all purposes.

\section{Standard solution}

Standard stock solution of BU was prepared in methanol to obtain a concentration of $500 \mu \mathrm{gmL}^{-1}$.

\section{Working standard solutions}

Working standard solutions at nine levels were prepared by appropriately diluting standard stock solution in the concentration range of $1.0-500 \mu \mathrm{gmL}^{-1}$ for BU. Samples in triplicates were prepared for each concentration and peak areas were plotted against the corresponding concentrations to obtain the calibration graph as shown in Fig. 2.

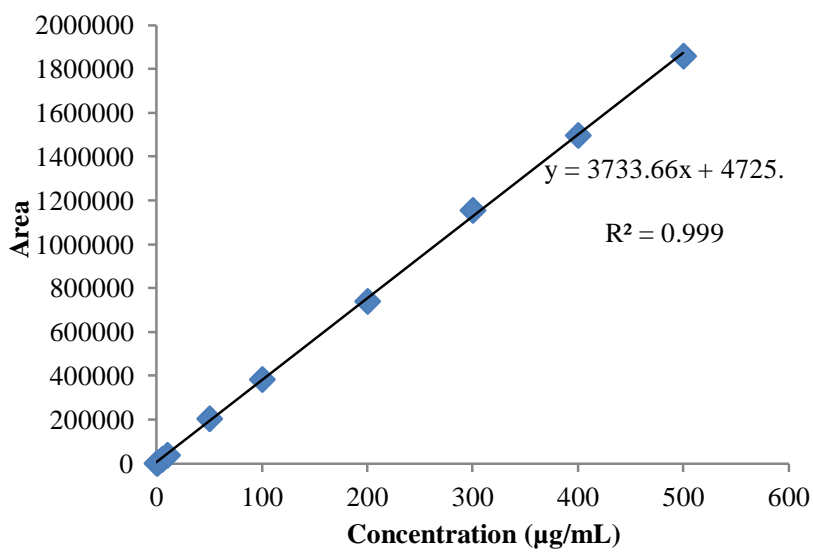

Fig. 2: Calibration graph for Buprenorphine $\mathrm{HCl}$

\section{Sample preparation}

The accurately weighed quantity of ME containing equivalent to about $4.0 \mathrm{mg}$ dose of $\mathrm{BU}$ was accurately weighed and transferred to a $100 \mathrm{~mL}$ volumetric flask. Approximately 15 $\mathrm{mL}$ of methanol was added to the flask and the contents were vortex-mixed for $10 \mathrm{~min}$. The flask was adjusted to volume with the mobile phase and mixed well. The resulting solution was filtered using $0.45 \mu \mathrm{m}$ Polytetrafluorethylene (PTFE) filter into standard analytical glass vials and injected into the HPLC. Samples were prepared in triplicate and injected into the HPLC.

\section{METHOD DEVELOPMENT}

\section{Instrumentation and chromatographic conditions}

The HPLC system consisted of a LC-2010C HT LIQUID CHROMATOGRAPHY SHIMADZU (Kyoto, Japan) equipped with a quaternary pump, online degasser, column heater, autosampler and UV detector. Data collection and analyses were performed using SHIMADZU LC Solution software. Separation was achieved on C-18 column, PrincetonSPHER -100 C18 HPLC column $(250 \mathrm{~mm} \times 4.6 \mathrm{~mm}, 5 \mu \mathrm{m})$. The elution was isocratic with mobile phase consisting of acetonitrile and $10 \mathrm{mmolL}^{-1}$ potassium phosphate buffer adjusted to $\mathrm{pH} 6.0$ with triethanolamine $(83: 17$, $\mathrm{v} / \mathrm{v})$. The flow rate was $1.0 \mathrm{mLmin}^{-1}$ that yielded a backpressure of about 1654 psi. The column temperature was maintained at $30^{\circ} \mathrm{C}$, the detection was monitored at a wavelength of $284 \mathrm{~nm}$ and injection volume was $20 \mu \mathrm{L}$.

\section{Instrumentation and chromatographic conditions for forced degradation study}

The forced degradation studies carried out using UFLC system consisted of a LC-30 AD Nexera Liquid Chromatography (Spinotech Pvt Ltd) equipped with a online degasser (DGU-20As 
prominence degasser), column heater (CTO-20 AC prominence column oven), auto sampler (Sil-30AC Nexera auto sampler) and UV detector (SPD-20 A prominence UV/vis detector) and DAD detector (SPD-M 20A prominence diode array detector was used to determine the peak purity. Analysis was performed at ambient temperature and detection was carried out in the range of $200-$ $400 \mathrm{~nm}$. Column specifications, mobile phase, flow rate and injection volume was same as mention under Instrumentation and chromatographic conditions.

\section{Calibration graph for chromatographic measurement of $\mathrm{BU}$}

The area were measured for BU in the concentration range of 1.0, 5.0, 10.0, 50.0, 100.0, 200.0, 300.0, 400.0, 500.0 $\mu \mathrm{g}$ $\mathrm{ml}^{-1}$ using above mentioned chromatographic conditions. Calibration graphs were plotted for BU at concentration range of 1.0-500 $\mathrm{g} \mathrm{ml}^{-1}$ as shown in Fig. 2.

\section{UV spectrum of Placebo ME}

The accurately measured amount of placebo ME taken in $10.0 \mathrm{~mL}$ of volumetric flask and volume was made with methanol. This solution was then scanned from 200 to $400 \mathrm{~nm}$ with the UV spectrophotometer (Shimadzu $1800 \mathrm{UV}-\mathrm{Vis}$ double beam spectrophotometer with UV probe software) using methanol as a blank. The UV spectrum of placebo ME system containing Tween 20 was shown in the Fig.3.

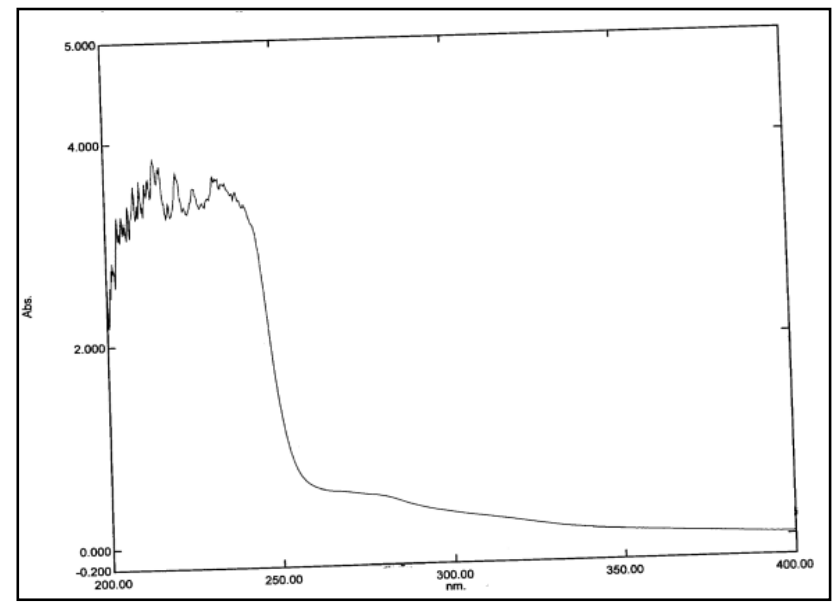

Fig. 3: UV spectrum of placebo ME system containing Tween 20.

\section{UV spectrum of Buprenorphine $\mathrm{HCl}$}

Stock solution of BU was prepared by dissolving 20.0 $\mathrm{mg}$ of BU in $50 \mathrm{ml}$ volumetric flask and volume was made with methanol. Further working standard solution was prepared by pipetting $5.0 \mathrm{ml}$ of stock solution in $10 \mathrm{ml}$ volumetric flask and volume was made with methanol to get concentration of $200.0 \mu \mathrm{g}$ $\mathrm{ml}^{-1}$ of BU. This solution was then scanned from 250 to $400 \mathrm{~nm}$ with the UV spectrophotometer (Shimadzu 1800 UV-Vis double beam spectrophotometer with UV probe software) using methanol as a blank. The UV spectrum of BU was shown in the Fig.4.

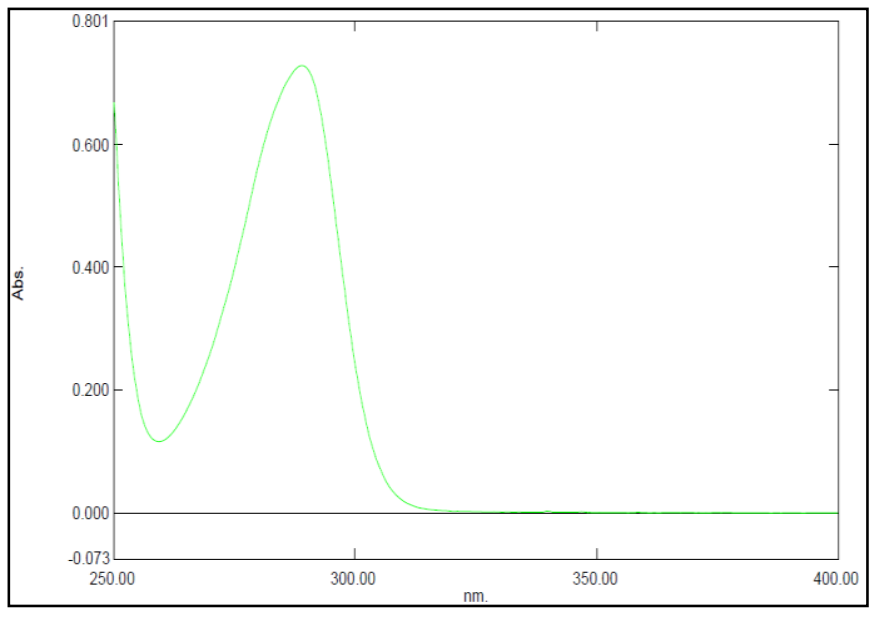

Fig. 4: UV spectrum of Buprenorphine $\mathrm{HCl}$.

\section{METHOD VALIDATION}

The method was validated according to the $\mathrm{ICH}$ guidelines (ICH, 2005). The following validation characteristics were addressed: linearity, accuracy, precision, specificity, limits of detection and quantitation and robustness.

\section{System suitability testing (SST)}

System suitability standard solution containing 40 $\mu \mathrm{gmL}^{-1}$ of BU was prepared by appropriately diluting and mixing the standard stock solution. System suitability was determined by injecting six injections of the system suitability standard before sample analysis.

\section{Linearity and range}

Standard calibration curve for BU was prepared with nine calibrations over a concentration range of $1.0-500.0 \mu \mathrm{gmL}^{-1}$ in triplicate. The data of peak area versus concentration were treated by linear least square regression analysis.

\section{Accuracy}

To study the reliability and suitability of the developed method, recovery experiments carried out. Placebo samples spiked with different amount of BU at 50, 100 and $150 \%$ in duplicate for each one $(n=6)$ over the theoretical values. Measured values were compared with the theoretical concentration. Recovery for pharmaceutical formulations should be within the range $100 \pm 5$ $\%$. The \% R.S.D. of each measurement determined, which should be less than $2 \%$.

\section{Precision}

The precision of the developed method was assessed in terms of repeatability and intermediate precision by analyzing 40 $\mu \mathrm{gmL}^{-1} \mathrm{BU}$ sample solution in triplicate. The $\%$ R.S.D. values of the results corresponding to the peak area and retention time were expressed for intra-day precision and for 3 days for inter-day precision. 


\section{Specificity}

Placebo samples was analysed to demonstrate absence of interference with the elution of the BU. For determining selectivity of the method, placebo containing all the excipients used in the formulation of $\mathrm{ME}$, was analyzed. All chromatograms were examined to determine if BU was co-eluted with any additional excipients peak.

\section{Limits of Detection and Quantization (LOD and LOQ)}

LOD and LOQ were calculated based on the standard deviation of the response and the slope of the calibration curve. The standard deviation of y-intercepts of regression lines was used as the standard deviation of responses ( $\mathrm{ICH}, 2005)$. These values were obtained using the following equations:

$$
\begin{array}{ll}
\mathrm{LOD}=3.3 \sigma / \mathrm{S} & \text { (Eq. 1) } \\
\mathrm{LOQ}=10.0 \sigma / \mathrm{S} & \text { (Eq. 2) }
\end{array}
$$

Where, $\sigma=$ the standard deviation of the response

$\mathrm{S}=$ the slope of the calibration curve

\section{Robustness}

The robustness of the method was evaluated by analyzing the system suitability standards and evaluating system suitability parameter data after varying, individually, the HPLC pump flow rate $( \pm 10 \%)$ and column compartment temperature $( \pm 14 \%)$.

\section{Forced degradation studies of buprenorphine $\mathrm{HCl}$ microemulsion}

Forced degradation studies of BU ME carried out under stress conditions according to $\mathrm{ICH}$ regulatory guidance Q1A (R2) (ICH, 2003). The ME formulation and its placebo used for the forced degradation studies to show the stability of BU under stress conditions and specificity of proposed method.

\section{Hydrolytic condition: acid, base, water induced degradation}

Appropriate quantity of BU ME containing $2.0 \mathrm{mg}$ of BU was treated with $5.0 \mathrm{ml}$ of $0.05 \mathrm{M} \mathrm{HCl}, 0.05 \mathrm{M} \mathrm{NaOH}$ and water separately. These samples were refluxed for $1 \mathrm{hr}$ at $60^{\circ} \mathrm{C}$ in a heating bath (Equitron Round Bath, Medica Instrument Mfg co.). After cooling, the solutions were neutralized with $5.0 \mathrm{ml}$ of $0.05 \mathrm{M}$ $\mathrm{NaOH}$ and $0.05 \mathrm{M} \mathrm{HCl}$ for acid and base induced degradation studies respectively and the solutions were diluted with $10.0 \mathrm{ml}$ of methanol and further volume was made up with mobile phase in a $50.0 \mathrm{~mL}$ volumetric flask. Accurately measured $4.0 \mathrm{~mL}$ of each solution was pipetted in $10.0 \mathrm{~mL}$ volumetric flask and volume was made up with mobile phase. These acid, base and water induced degradation studies were repeated for placebo ME giving similar treatment as given to BU ME. These samples were filtered using a $0.22 \mu \mathrm{m}$ membrane syringe filter and injected into prominence UFLC system with DAD detector. The total chromatographic run time was about double the retention of the drug peak.
Oxidative condition: hydrogen peroxide induced degradation

Appropriate quantity of BU ME containing $2.0 \mathrm{mg}$ of BU treated with $5.0 \mathrm{ml}$ of $30 \% \mathrm{H}_{2} \mathrm{O}_{2}$ and refluxed for $1 \mathrm{hr}$ at $60^{\circ} \mathrm{C}$ in a heating bath (Equitron Round Bath, Medica Instrument Mfg co.). After cooling, same treatment was given to this solution as described under hydrolytic condition: acid, base, water induced degradation. The same experiment repeated for placebo ME.

\section{Thermal degradation study}

Appropriate quantity BU ME containing $2.0 \mathrm{mg}$ of $\mathrm{BU}$ and placebo ME weighed accurately and placed in glass vial and subjected to heat at $60^{\circ} \mathrm{C}$ in a hot air oven (Naano Lab India) for 5 $\mathrm{hr}$, then diluted with methanol and mobile phase and analysed as described under hydrolytic condition: acid, base, water induced degradation.

\section{Photolytic degradation study}

The photochemical stability of the drug studied by exposing same amount of BU ME and placebo ME to sunlight for $5 \mathrm{hr}$. Then the volume made upto $50.0 \mathrm{~mL}$ with methanol. $4.0 \mathrm{~mL}$ of this solution was pipette in $10.0 \mathrm{~mL}$ of volumetric flask and volume made with mobile phase.

\section{RESULTS AND DISCUSSION}

\section{Method development and optimization}

BU being highly soluble in methanol i.e. $42.0 \mathrm{mg} / \mathrm{mL}$, hence it is used as solvent for standard and sample preparation (Elephant Care International, 2016). The tween 20 present in the placebo ME system showed absorbance in the range of 200-250 $\mathrm{nm}$ (Fig. 3.), when scanned in the UV visible range of 200-400 nm. Hence the previously reported HPLC method for the determination of $\mathrm{BU}$ in tablet formulation using detection wavelength at $210.0 \mathrm{~nm}$ (Mostafavi et al., 2009) was not suitable for estimation of BU in MEs. The UV spectrum of BU as shown in the Fig. 4, exhibits the $\lambda_{\max }$ of BU at $289.0 \mathrm{~nm}$ in methanol. But, the HPLC method was developed using $284.0 \mathrm{~nm}$ as detection wavelength for $\mathrm{BU}$, since at this wavelength no interference of excipients was observed.

Typically, method development focused on identifying buffer type, strength and $\mathrm{pH}$, organic solvent concentration and implementing small changes to optimize selectivity and enhance resolution. At the first stage, a C-18 column with water, methanol and $0.1 \%$ orthophosphoric acid $(65: 25: 10 \mathrm{v} / \mathrm{v} / \mathrm{v})$ at $\mathrm{pH} 3.2$ was used as mobile phase. Though the column was previously washed and saturated with mobile phase, peak splitting of BU was observed. Subsequently, the splitting of the peak was overcome by increasing the $\mathrm{pH}$ of the mobile phase to 4.4 , but the peak shape was not acceptable. 


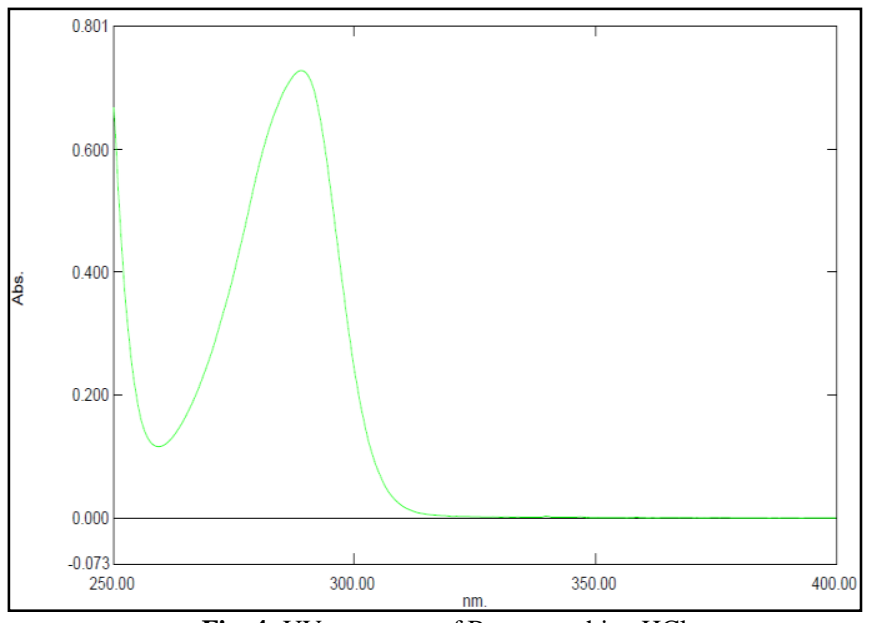

Fig. 4: UV spectrum of Buprenorphine $\mathrm{HCl}$.

Then, in another trial, the $\mathrm{pH}$ of the mobile phase was kept at 4.4 and the ratio of methanol in the mobile phase increased to $30 \%$ and then to $40 \%$, but the broadness of the BU peak further goes on increasing.

At the second stage, a C-18 column and potassium phosphate buffer, $\mathrm{pH}$ 3.0, was used with acetonitrile as the organic solvent. Though the column was base activated for improved peak shape of basic compound, the peak symmetry of the compound was poor. Subsequently, an acceptable peak shape was achieved by increasing the buffer $\mathrm{pH}$ to 6.0 , using $83 \%$ of acetonitrile as organic solvent. For optimum resolution and peak symmetry, the mobile phase used consists of $10 \mathrm{mmol} \mathrm{L}^{-1}$ potassium phosphate buffer adjusted to $\mathrm{pH} 6.0$ with triethanolamine and acetonitrile $(17: 83, \mathrm{v} / \mathrm{v})$. To improve repeatability of runs and reduce back pressure, which is important to extending the column life time, the column oven temperature was set at optimum $30 \mathrm{C}$. In the optimized conditions, BU exhibited a sharp peak with better resolution. The optimal wavelength was established experimentally after measuring all spectra in mobile phase and testing the detector response using UV absorbance scanned over the range of $200-400 \mathrm{~nm}$. Although the absorbance maxima recommended by $\mathrm{BP}$ for $\mathrm{BU}$ was $288 \mathrm{~nm}$; it was shown that 284 $\mathrm{nm}$ is the optimal wavelength to maximize the sensitivity and has no interference with other components of the formulation.

\section{Method validation}

Developed method must be validated before practical use. By following the ICH guidelines for analytical method validation, Q2 (R1), the SST was performed and the validation characteristics were addressed.

\section{System suitability}

The system suitability test ensures the validity of the analytical procedure as well as confirms the resolution between different peaks of interest. All critical parameters tested met the acceptance criteria on all days. Representative chromatograms obtained for the mobile phase, placebo and BU standard solution of $40 \mu \mathrm{gmL}^{-1}$, shown in the chromatogram, the analyte was eluted by forming symmetrical single peak and was well separated from the solvent front (Fig. 5).
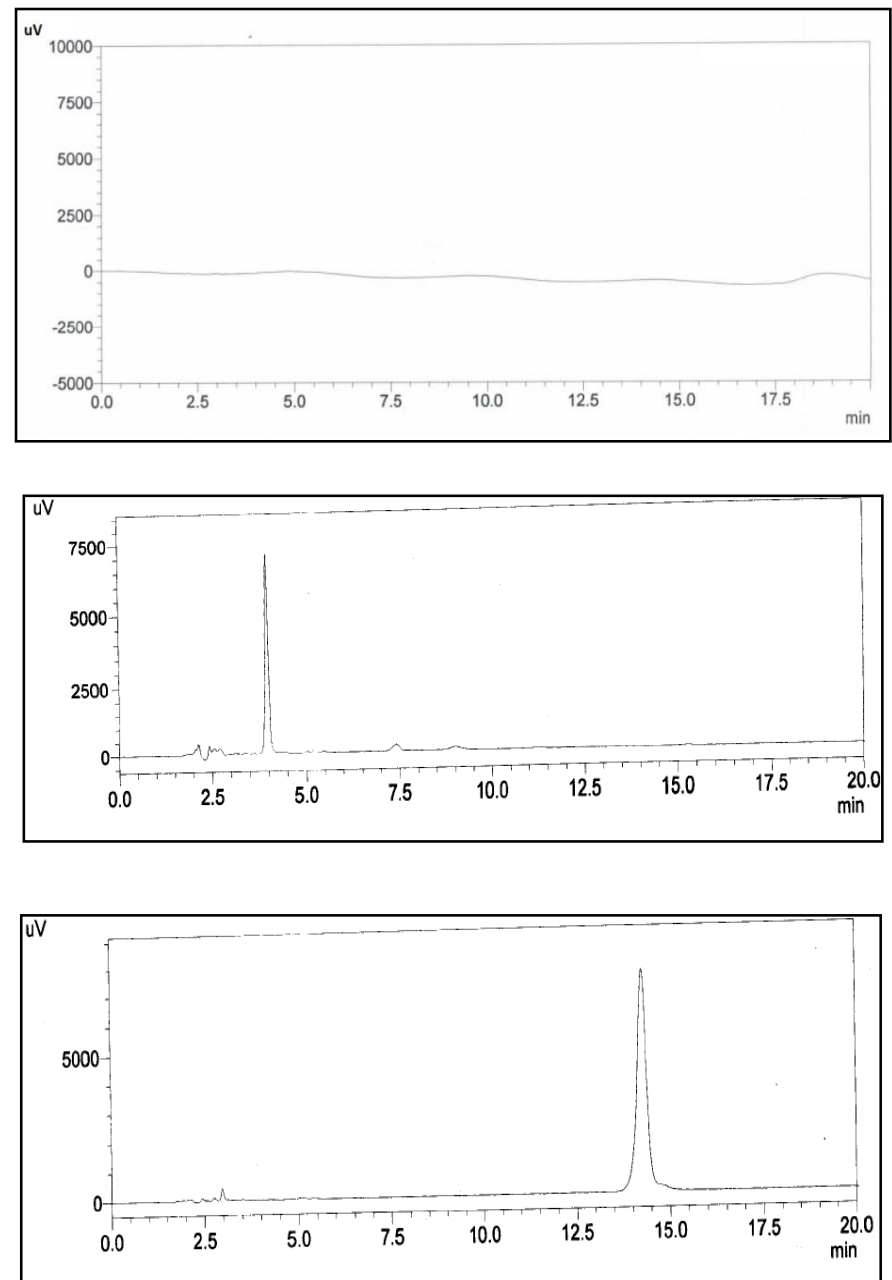

Fig. 5: Representative chromatograms obtained for the mobile phase, placebo and BU standard corresponding to the $40 \mu \mathrm{gmL}^{-1}$.

\section{Linearity and range}

The results, summarized in Table 1, shows that a good correlation exists between analyte peak area and concentration as denoted by $\mathrm{R}^{2}$ value (0.999) and in the range of $1.0 \mu \mathrm{gmL}^{-1}$ to $500.0 \mu \mathrm{gmL}^{-1}$. The Fig. 1 shows the average plot area verses concentration $\mu \mathrm{gmL}^{-1}$ for the determination performed in triplicate.

Table 1: Linearity parameters for the estimation of BU.

\begin{tabular}{lc}
\hline \multicolumn{1}{c}{ Parameters (Units) } & Buprenorphine hydrochloride \\
\hline Linearity range $\left(\mu \mathrm{g} \mathrm{mL}^{-1}\right)$ & $1.0-500$ \\
Slope & $3733.66 \pm 1.15$ \\
Intercept & $4725.0 \pm 5.29$ \\
Coefficient of determination $\left(\mathrm{R}^{2}\right)$ & $0.999 \pm 0.0001$ \\
\hline
\end{tabular}

Values are reported as mean \pm S.D. of three calibration curves generated on three consecutive days $(n=3)$. Nine concentrations in the linearity range were evenly distributed. 


\section{Accuracy}

The reliability and suitability of the developed method studied using recovery experiments. For determining accuracy, placebo samples were spiked with different amount of BU at 50, 100 and $150 \%$ in duplicate for each spiked amount over the theoretical values. The recovery was $100 \pm 5 \%$ for all samples with \% R.S.D. less than $2 \%$ (Table 2). This indicated that the developed method is accurate.

Table 2: Method validation results for BU.

\begin{tabular}{|c|c|}
\hline Parameters (Units) & $\begin{array}{l}\text { Buprenorphine } \\
\text { hydrochloride }\end{array}$ \\
\hline \multicolumn{2}{|l|}{ SST } \\
\hline Theoretical plates & 14856.925 \\
\hline Peak Area (A) (\% R.S.D.) & 0.561 \\
\hline Retention time $\left(t_{R}\right)(\%$ R.S.D.) & 0.218 \\
\hline Tailing Factor (\% R.S.D.) & 0.465 \\
\hline Repeatability $^{\mathrm{a}}$, Theoretical plates (\% R.S.D.) & 1.506 \\
\hline Repeatability $^{\mathrm{a}}$, (A) (\% R.S.D.) & 1.375 \\
\hline Repeatability $^{\mathrm{a}},\left(\mathrm{t}_{\mathrm{R}}\right)$ (\% R.S.D.) & 1.046 \\
\hline Repeatability ${ }^{a}$, Tailing Factor (\% R.S.D.) & 1.257 \\
\hline \multicolumn{2}{|l|}{ Validation } \\
\hline Precision $^{\mathrm{b}}$, Theoretical plates (\% R.S.D.) & 1.658 \\
\hline Precision $^{\mathrm{b}}$, (A) (\% R.S.D.) & 0.823 \\
\hline Precision $^{\mathrm{b}},\left(\mathrm{t}_{\mathrm{R}}\right)(\%$ R.S.D. $)$ & 0.604 \\
\hline Precision ${ }^{\mathrm{b}}$, Tailing Factor (\% R.S.D.) & 0.754 \\
\hline Accuracy (50\% recovery studies) & 99.75 \\
\hline Accuracy (50 \% recovery studies) (\% R.S.D.) & 0.622 \\
\hline Accuracy (100\% recovery studies) & 99.93 \\
\hline Accuracy (100 \% recovery studies) (\% R.S.D.) & 0.436 \\
\hline Accuracy ( $150 \%$ recovery studies) & 95.09 \\
\hline Accuracy (150 \% recovery studies) (\% R.S.D.) & 0.128 \\
\hline Specificity & No interference \\
\hline \multicolumn{2}{|l|}{ Sensitivity } \\
\hline $\operatorname{LOD}\left(\mu \mathrm{g} \mathrm{mL}^{-1}\right)$ & 0.0046 \\
\hline $\operatorname{LOQ}\left(\mu \mathrm{g} \mathrm{mL} \mathrm{m}^{-1}\right)$ & 0.0141 \\
\hline
\end{tabular}

\section{Precision}

Intra and inter day precisions were established across the analytical range for BU. The intra- and inter-day precision was calculated using BU standard solution of $40 \mu_{\mathrm{gmL}}{ }^{-1}$ (Table 2). Repeatability (intra-day precision) of the analytical method was found to be reliable based on \% R.S.D. (1.506, 1.375, 1.046 and 1.257) corresponding to the theoretical plates, peak areas, retention times and tailing factor. Similarly, repeatability (inter-day precision) was demonstrated on different days and evaluating the data for theoretical plates, peak areas, retention times and tailing factor that cover the assay method range. The \% R.S.D. values were $1.658,0.823,0.604$ and 0.754 for all evaluated data of interday precision and illustrated the good precision for the analytical method.

\section{Specificity}

Injections of the placebo demonstrated absence of interference with the elution of the drug. These results proved that there was no interference from other materials in the ME formulation; therefore, confirmed the specificity of the method (Fig. 5).

\section{Limits of Detection and Quantization (LOD and LOQ)}

The limit of detection and limit of quantitation determine sensitivity of the method. The LOD and LOQ for BU were 0.0046 $\mu \mathrm{g} \mathrm{ml}^{-1}$ and $0.0141 \mu \mathrm{g} \mathrm{ml}^{-1}$, respectively. These values show that the proposed method has good sensitivity and results are presented in Table 2.

\section{Robustness}

To make sure the insensitivity of the developed HPLC method to minor changes in the experimental conditions, it is important to show its robustness. None of the alterations caused a significant change in peak area and retention time for BU (Table 3 ). Although the changes in retention times and area were more significant, with increase or decrease in flow rate and temperature, but quantitation was still possible.

Table 3: Method validation data for robustness study of BU.

\begin{tabular}{|c|c|c|c|c|}
\hline Parameter altered (Units) & $\underset{2}{\stackrel{d}{Z}}$ & 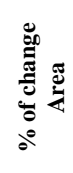 & 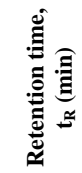 & 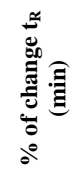 \\
\hline Increased flow rate $\left(1.1 \mathrm{~mL} \mathrm{~min}^{-1}\right)$ & 140135 & 8.21 & 12.974 & 9.00 \\
\hline Decreased flow rate $\left(0.9 \mathrm{~mL} \mathrm{~min}^{-1}\right)$ & 160199 & 4.92 & 15.609 & 9.47 \\
\hline Increased column temperature $\left(35^{\circ} \mathrm{C}\right)$ & 144657 & 5.25 & 14.293 & 0.24 \\
\hline Decreased column temperature $\left(25^{\circ} \mathrm{C}\right)$ & 138870 & 9.04 & 14.847 & 4.13 \\
\hline
\end{tabular}

\section{Analysis of the developed microemulsion formulation}

The validated method was used in the analysis of developed BU ME formulation with dose strength of $4.0 \mathrm{mg} \mathrm{BU}$ per unit. Representative chromatogram is shown in Fig. 6. The result for the drugs assay was in good agreement with the label claims. BU content was between 99.10 and $100.4 \%$.

\section{Forced degradation study/specificity}

Forced degradation studies performed on BU ME and its placebo demonstrated selectivity and stability indicating capability of the proposed RP-HPLC method. Accordingly the degradation stress studies were conducted by exposing BU to acid, base, peroxide, water, light and heat.

Observed that around $2.42 \%$ and $3.59 \%$ drug degradation (Table 4) obtained on refluxing at $60^{\circ} \mathrm{C}$ in $0.05 \mathrm{M} \mathrm{HCl}$ and $0.05 \mathrm{M}$ $\mathrm{NaOH}$ for $1 \mathrm{hr}$, respectively; but there was no elution of corresponding degradation products as compared to the standard unstressed solution of BU ME as well as its placebo (Fig. 7 (a, b) and Fig. $8(\mathrm{a}, \mathrm{b}))$. In neutral condition negligible amount of degradation observed i.e. $0.06 \%$ on refluxing at $60^{\circ} \mathrm{C}$ for $1 \mathrm{hr}$ (Fig. 7 (c) and Fig. 8 (c)). Peak purity index for BU peak in acidic, basic and neutral condition was within acceptance criteria i.e. not less than 0.990 as shown in Fig. 9 (a, b and c). 
Table 4: Forced degradation study data for BU ME.

\begin{tabular}{|c|c|c|c|c|}
\hline \multirow{2}{*}{ Stress condition } & \multirow{2}{*}{$\begin{array}{c}\text { Assay degraded/ Unstressed } \\
\text { sample (\%) }\end{array}$} & \multicolumn{3}{|c|}{ Peak purity test for $\mathrm{BU}$ peak } \\
\hline & & Impurity & Peak purity index & Single point Threshold \\
\hline Unstressed & 99.29 & Not Detected & 1.00 & 0.999 \\
\hline Acidic $(5.0 \mathrm{~mL} 0.05 \mathrm{M} \mathrm{HCl}) 60^{\circ} \mathrm{C}, 1 \mathrm{hr}$ & 96.87 & Not Detected & 1.00 & 0.999 \\
\hline Alkaline $(5.0 \mathrm{~mL} 0.05 \mathrm{M} \mathrm{NaOH}) 60^{\circ} \mathrm{C}, 1 \mathrm{hr}$ & 95.71 & Not Detected & 1.00 & 0.999 \\
\hline Neutral $\left(5.0 \mathrm{~mL} \mathrm{H}_{2} \mathrm{O}\right) 60^{\circ} \mathrm{C}, 1 \mathrm{hr}$ & 99.23 & Not Detected & 0.99 & 0.999 \\
\hline Oxidation $\left(5.0 \mathrm{~mL} 30 \% \mathrm{H}_{2} \mathrm{O}_{2}\right) 60^{\circ} \mathrm{C}, 1 \mathrm{hr}$ & 78.30 & Not Detected & 1.00 & 0.999 \\
\hline Thermal $60^{\circ} \mathrm{C}, 1 \mathrm{hr}$ & 97.95 & Not Detected & 1.00 & 0.999 \\
\hline Photolytic (daylight) $5 \mathrm{hr}$ & 99.27 & Not Detected & 1.00 & 0.999 \\
\hline
\end{tabular}

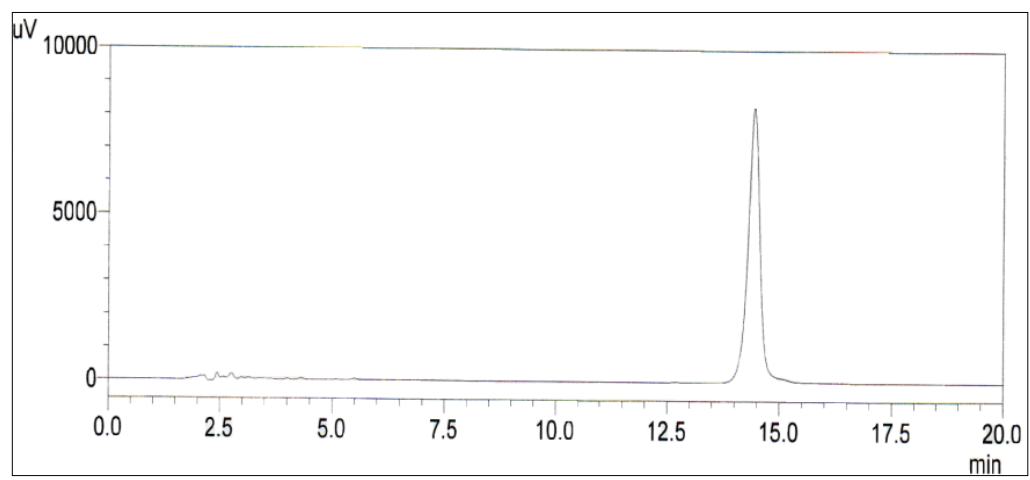

Fig. 6: Representative chromatogram obtained for developed BU ME

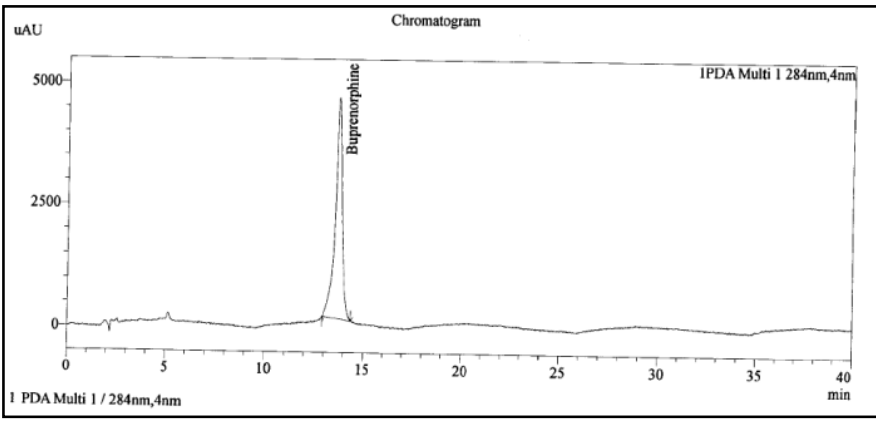

A

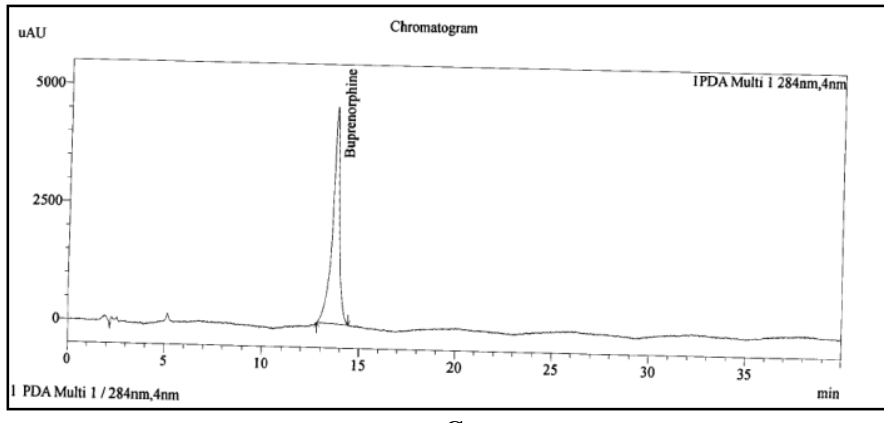

C

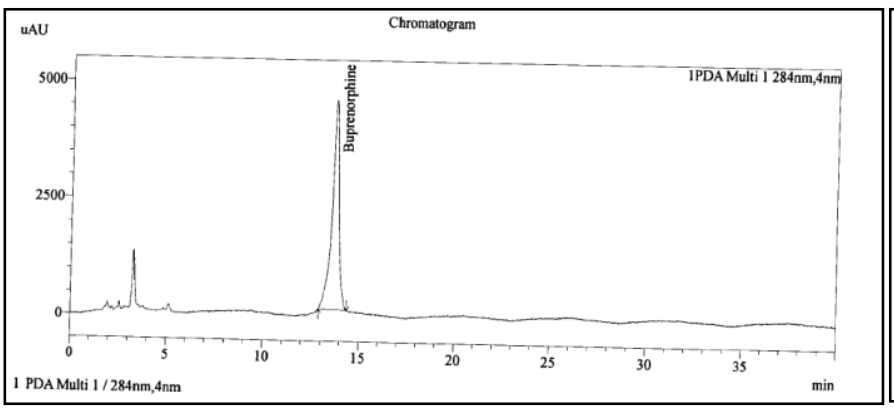

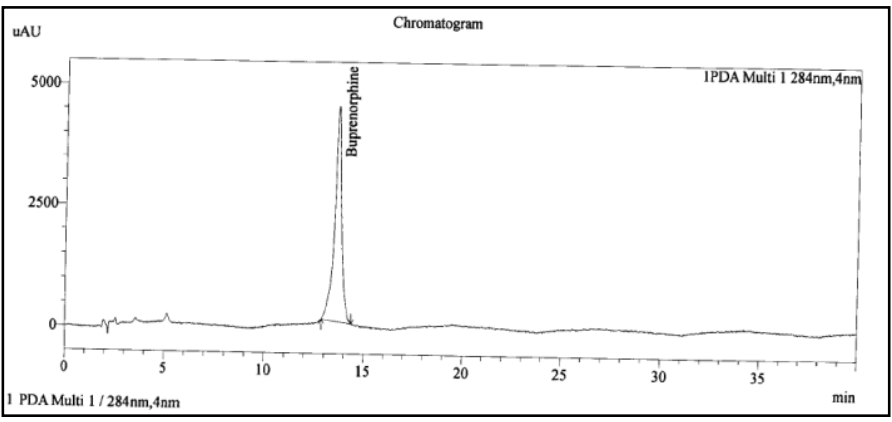

B

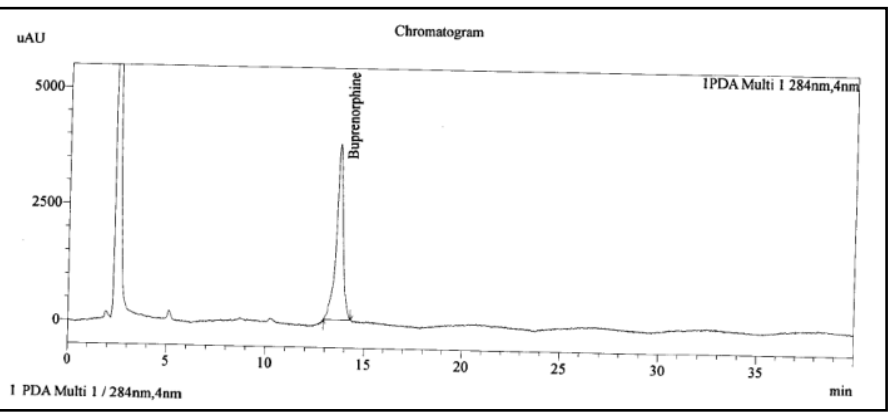

D

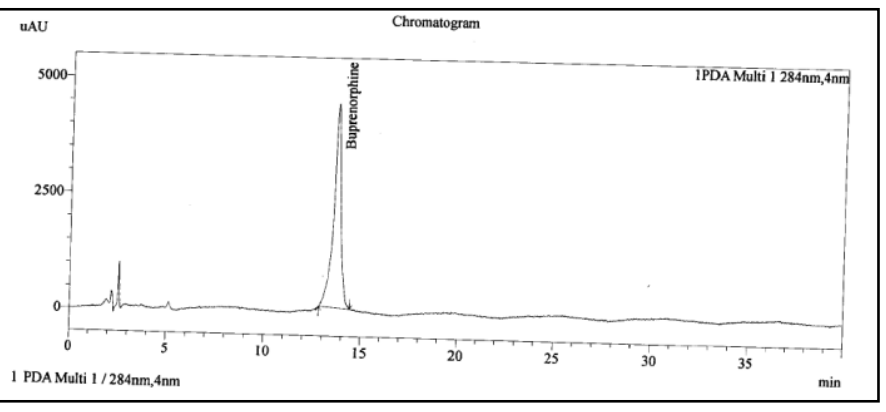




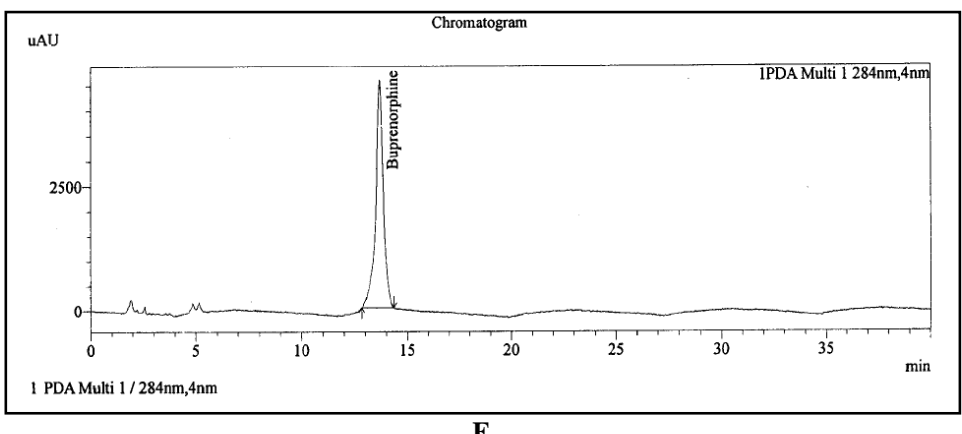

Fig. 7: Fig. 7: $\mathrm{HPLC}$ chromatogram of $\mathrm{BU} \mathrm{ME}$ in $(\mathrm{A}) 0.05 \mathrm{HCl}$ at $0{ }^{\circ} \mathrm{C}(\mathrm{B}) 0.05 \mathrm{M} \mathrm{NaOH}$ at $0 \mathrm{C}$; (C) neutral condition $\left(\mathrm{H}_{2} \mathrm{O}\right)$ at $0{ }^{\circ} \mathrm{C}$; $(\mathrm{D})$ oxidative condition $(\mathrm{H} 2 \mathrm{O} 2)$ at $0{ }^{\circ} \mathrm{C}$; (E) Thermal degradation condition $0 \mathrm{C}$; (F) Photolytic degradation condition (exposure to sunlight); (G) Unstressed condition.
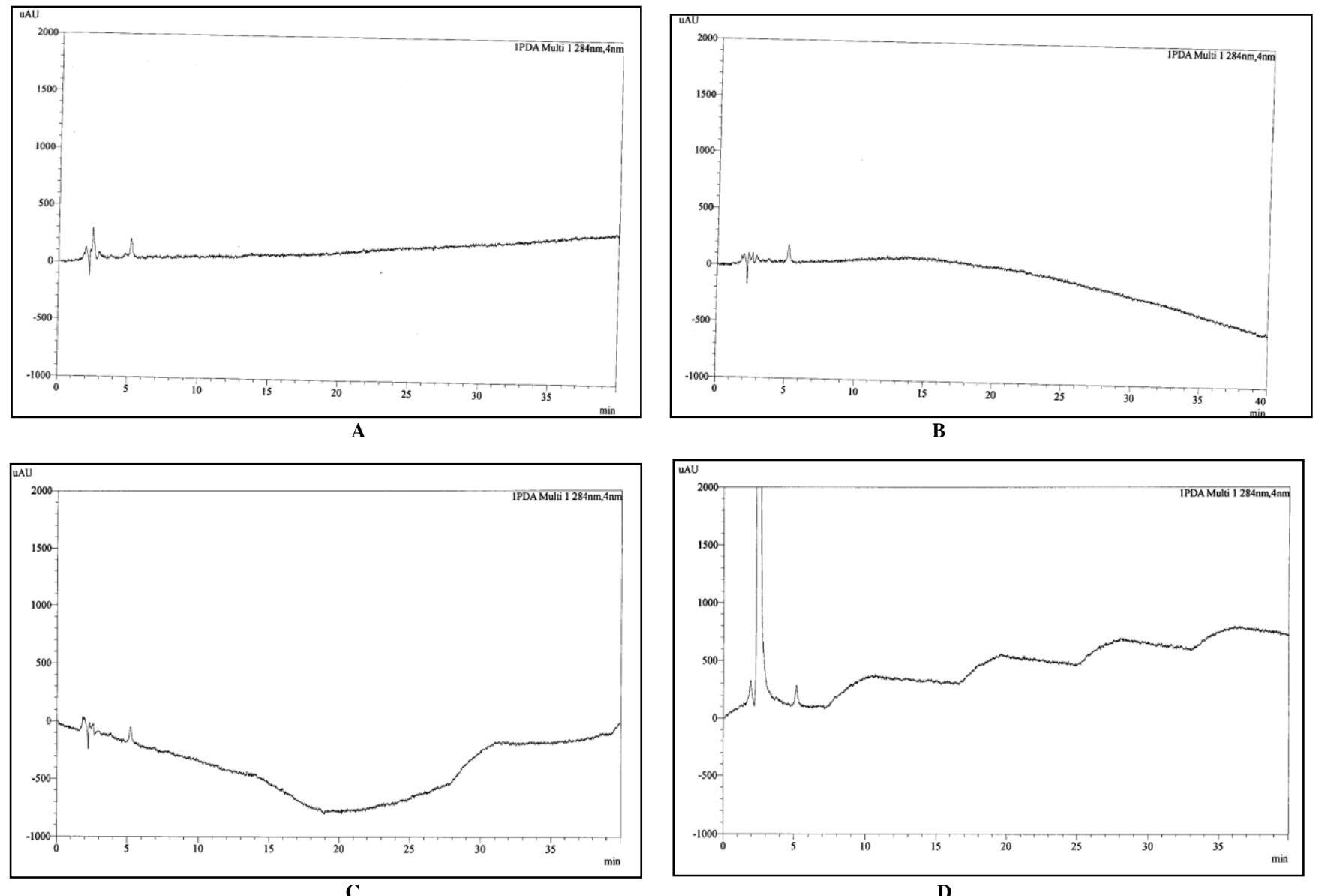

D
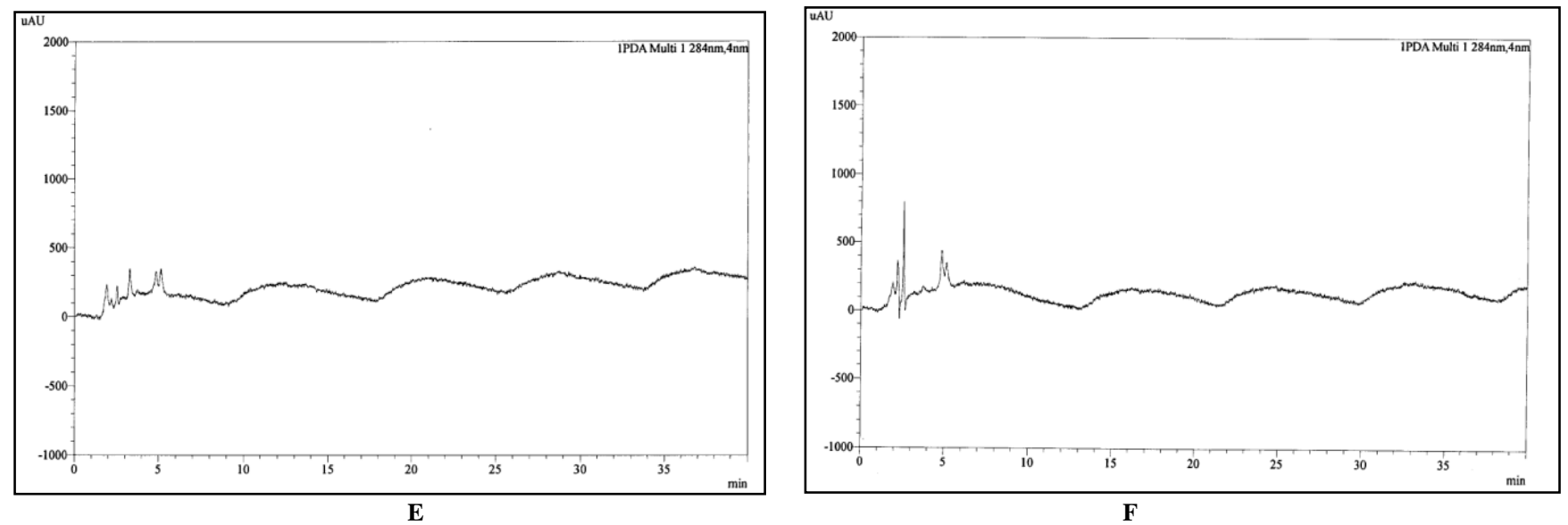


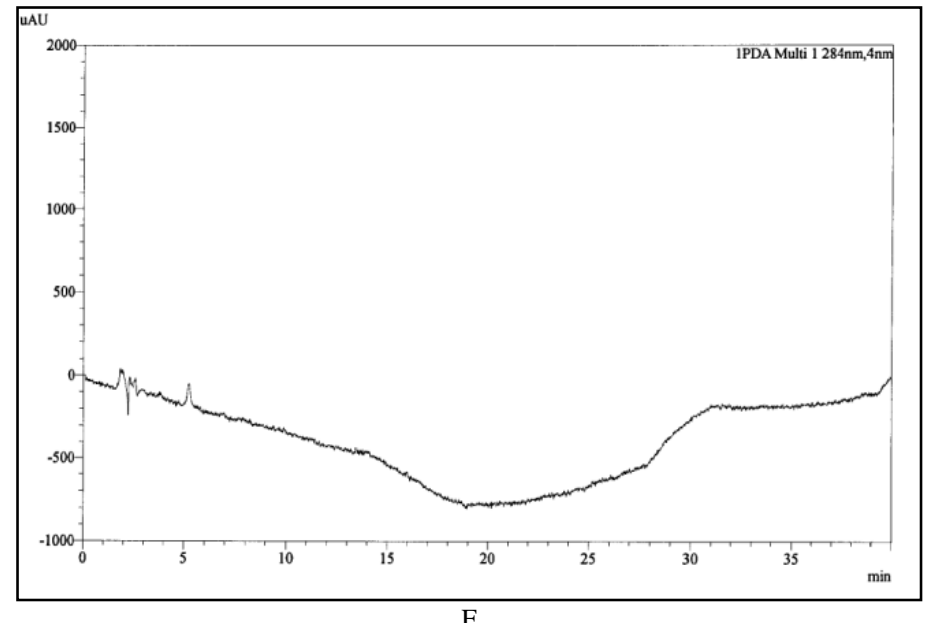

Fig. 8: HPLC chromatogram of placebo ME in (A) $0.05 \mathrm{M} \mathrm{HCl}$ at $60 \mathrm{C}$; (B) $0.05 \mathrm{M} \mathrm{NaOH}$ at $60 \mathrm{C}$; (C) neutral condition (H2O) at $60 \mathrm{C}$; (D) oxidative condition $\left(\mathrm{H}_{2} \mathrm{O}_{2}\right)$ at $60 \mathrm{C} ;(\mathrm{E})$ Thermal degradation condition $60 \mathrm{C} ;(\mathrm{F})$ Photolytic degradation condition (exposure to sunlight); (G) Unstressed condition.

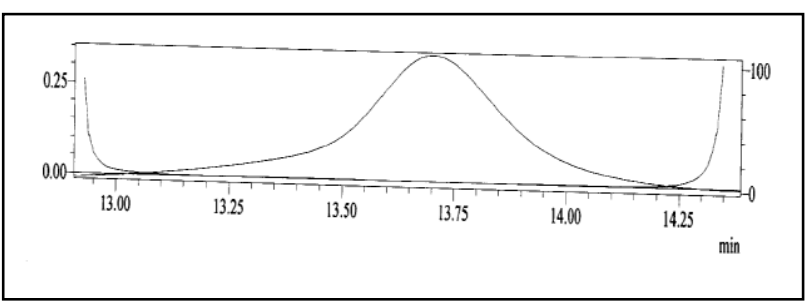

A

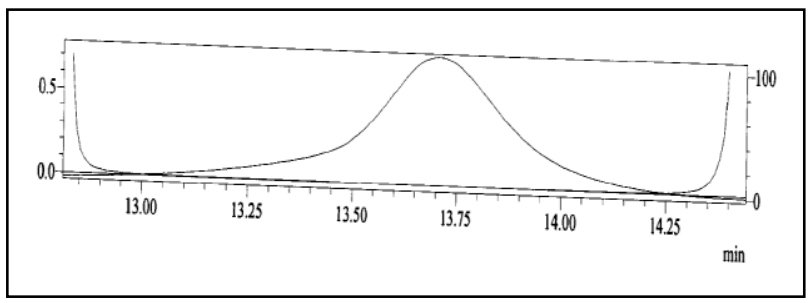

C

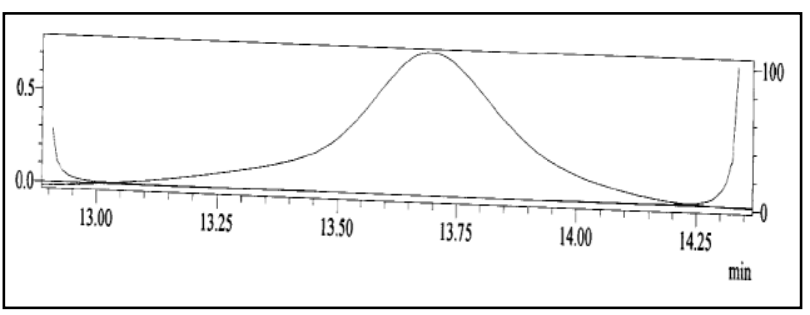

$\mathbf{E}$

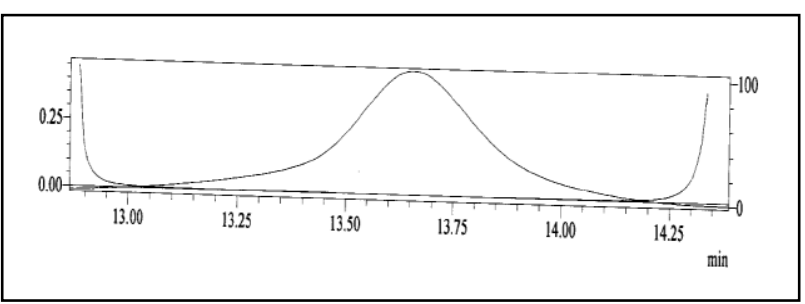

B

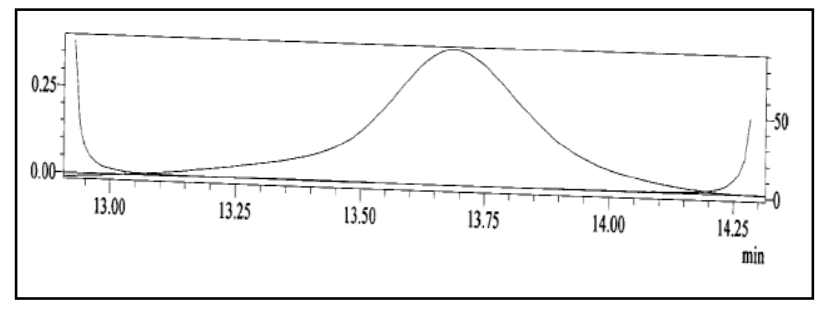

D

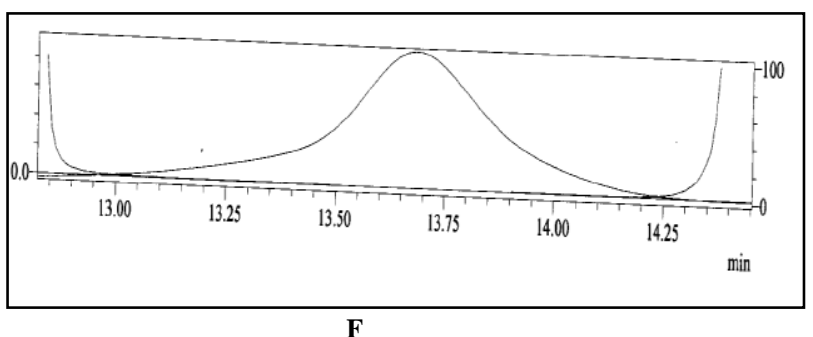

$\mathbf{F}$

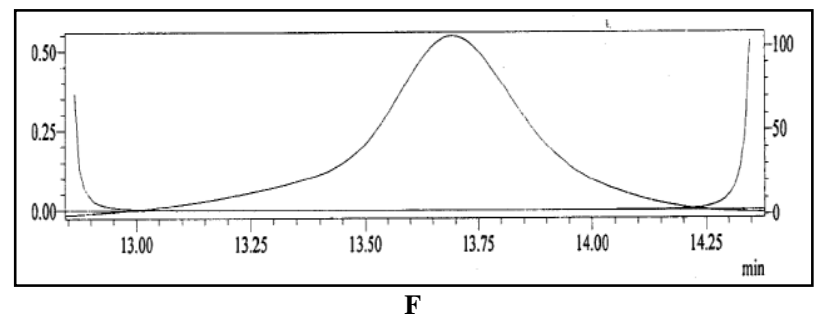

Fig. 9: Peak purity graph of buprenorphine $\mathrm{HCl}$ in (A) $0.05 \mathrm{M} \mathrm{HCl}$ at $60 \mathrm{C}$; (B) $0.05 \mathrm{M} \mathrm{NaOH}$ at $60 \mathrm{C}$; (C) neutral condition $\left(\mathrm{H}_{2} \mathrm{O}\right)$ at $60 \mathrm{C}$; (D) oxidative condition $\left(\mathrm{H}_{2} \mathrm{O}_{2}\right)$ at $60 \mathrm{C}$; (E) Thermal degradation condition at $60 \mathrm{C}$; (F) Photolytic degradation condition (exposure to sunlight); (G) Unstressed condition. 
Observed that around $20.99 \%$ drug degradation obtained on refluxing at $60^{\circ} \mathrm{C}$ in $30 \% \mathrm{H}_{2} \mathrm{O}_{2}$ for $1 \mathrm{hr}$ and there was no corresponding formation of degradation products as compared to its placebo when given the similar treatment as shown in Fig. 7 (d) and $8(\mathrm{~d})$. About $1.35 \%$ and $0.02 \%$ of degradation was observed in thermal and photolytic stress conditions as shown in Fig. 7 (e, f) and $8(\mathrm{e}, \mathrm{f})$, respectively. Peak purity index for BU peak in oxidative, thermal and photolytic condition was within acceptance criteria i.e. not less than 0.990, represented in Fig. 9 (d, e and f).

There was no interference of the sample diluents at the retention time of the $\mathrm{BU}$ peak. Moreover the peak purity test successfully passed for the BU peak in analysis of all the stressed samples and thus confirmed the spectral clearness of the principle peak. The purity and assay of BU was unaffected, which confirms that the developed method is stability-indicating method.

A simple, selective and precise stability indicating isocratic, reversed-phase HPLC method developed and found accurate, precise, linear and robust across the analytical range and robust. The method was specific for the determination of BU in a developed ME formulation. All the parameters met the criteria of the ICH guidelines for method validation. Forced degradation studies on BU ME and its placebo was conducted and the results revealed that the drug was liable under oxidative stress condition where as stable under acidic, basic and neutral hydrolysis, thermal and photolytic degradation conditions. The method could therefore be recommended for routine quality control analysis of raw material and various BU dosage formulations by assaying for potency and accuracy.

\section{PERMISSION}

License granted to M/s Zim Laboratories Ltd. by food and Drug Administration M.S. for working with Narcotic Drugs and Psychotropic Substances.

\section{ACKNOWLEDGEMENTS}

The authors are thankful to Centre for Advanced Research and Innovation (CARIn), Zim Laboratories, Kalmeshwar Dist. Nagpur (M.S.), India for providing the instrumentation and facilities and License for working with Narcotic opioid analgesic drugs. The authors are sincerely thankful to Government of India, Ministry of Science and Technology, Department of Science and Technology (DST), New Delhi for their thorough support. The authors are also thankful for our analytical research developmental laboratory team members for providing timely help.

\section{Financial support and sponsorship: Nil.}

Conflict of Interests: There are no conflicts of interest.

\section{REFERENCES}

Buprenorphine Hydrochloride. United States Pharmacopoeia 30 (USP) - National Formulary 25 (NF). The Official Compendia of Standards. United States Pharmacopeial Convention, 2007.
DRUGBANK Open Data Drug and Drug Target Database. Version 4.1. http://www.drugbank.ca/drugs/DB01183. [Accessed 12 June 2016].

Sweetman SC. 2009. Martindale the Complete Drug Reference. London: Pharmaceutical Press.

Ash JE, Budavari S, O'Neill M, Smith A, Heckelman PE, Kinneary J. 1996. The Merck Index. USA: Chapman and Hall.

Heel RC, Brogden RN, Speight TM. Buprenorphine: a review of its pharmacological properties and therapeutic efficacy. Drugs, 1979; 17: 81-110.

Hoskin PJ, Hanks GW. Opioid agonist-antagonist drugs in acute and chronic pain states. Drugs, 1991; 41: 326- 44.

U.S. National library of medicine. Dailymed.nlm.nih.gov/ dailymed/index.cfm. [Accessed 12 June 2016].

Everhart ET, Cheung P, Shwonek P. Subnanogramconcentration measurement of buprenorphine in human plasma by electron-capture capillary gas chromatography: application to pharmacokinetics of sublingual buprenorphine. Clin Chem, 1997; 43: 2292.

Tebbett IR. Analysis of buprenorphine by high performance liquid chromatography. J Chromatogr, 1985; 347: 411-13.

Hackett IP, Dusci LJ, Ilett KF. Sensitive screening method for buprenorphine in urine. J Chromatogr, 1986; 374: 400 - 4.

Liu SY, Liu KS, Kuei CH. Simultaneous determination of buprenorphine and its prodrug, buprenorphine propionate, by highperformance liquid chromatography with fluorescence detection: application to pharmacokinetic studies in rabbits. J Chromatogr B, 2005; 818: 233.

Garrett ER, Chandran VR. Pharmacokinetics of morphine and its surrogates. VI: bioanalysis, kinetics, solvolysis kinetics, solubility, pKa values, and protein binding of buprenorphine. J Pharm Sci, 1985; 74: 51524.

García-Fernández MA, Fernández-Abedul MT, Costa-García A. Determination of Buprenorphine in Biological samples by High Performance Liquid Chromatography with electrochemical detection. Chromatographia, 2001; 53: 704.

Polettini A, Huestis MA. Simultaneous determination of buprenorphine, norbuprenorphine, and buprenorphine-glucuronide in plasma by liquid chromatography-tandem mass spectrometry. J Chromatogr Biomed Appl, 1997; 692: 67.

Moody DE, Slawson MH, Strain EC. A Liquid Chromatographic-Electrospray Ionization-Tandem Mass Spectrometric method for determination of Buprenorphine, Its metabolite, norbuprenorphine and a coformulant, Naloxone, that is suitable for in vivo and in vitro metabolism studies. Anal Biochem, 2002; 306: 31.

Pirnay S, Hervé F, Bouchonnet S. Liquid chromatographic-electrospray ionization mass spectrometric quantitative analysis of buprenorphine, norbuprenorphine, nordiazepam and oxazepam in rat plasma. J Pharm Biomed Anal, 2006; 41: 1135.

Rodriguez-Rosas ME, Lofwall MR, Strain EC. Simultaneous determination of buprenorphine, norbuprenorphine and the enantiomers of methadone and its metabolite (EDDP) in human plasma by liquid chromatography/mass spectrometry. J Chromatogr B, 2007; 850: 538.

Mostafavi A, Abedi G, Jamshidi A, et al. Development and validation of a HPLC method for the determination of buprenorphine, naloxone hydrochloride and noroxymorphine in a tablet formulation. Talanta, 2009; 77: 1415-19.

Baboota S, Faiyaz S, Ahuja A, et al. Development and validation of a stability indicating HPLC method for analysis of celecoxib in bulk drug and microemulsion formulations. ACTA chromatographica, 2007; 18: 116-29.

Wuelfing WP, Kosuda K, Templeton AC, et al. Polysorbate 80 $\mathrm{UV} /$ vis spectral and chromatographic characteristic - defining boundary conditions for use of the surfactant in dissolution analysis. J Pharm Biomed Anal, 2006; 41: 774-82.

Johnson M. Detergents: Triton X-100, Tween 20, and more. Mater Methods, 2013; 3: 1-11. 
Text on validation of analytical procedures: text and methodology Q2 (R1), Triplicate International Conference on Harmonization (ICH) text, ICH Tech coordination; 2005.

Test on stability of new drug substances and products Q1A (R2), Triplicate International Conference on Harmonization (ICH) text, ICH Tech coordination; 2003.

Reynolds DW, Facchine KL, Mullaney JF, et al. Available guidance and best practices for conducting forced degradation studies. Pharmaceutical Technology, 2002:48e56. http://www.pharmtech.com.

Elephant Care International. The elephant formulary: Buprenorphine hydrochloride. http://www.elephantcare.org/

Drugs/buprenor.htm. [Accessed 12 June 2016].

\section{How to cite this article:}

Mundhey DA, Rajkondawar VV, Daud AS, Sapkal NP. A Study of Method Development, Validation and Forced Degradation for Quantification of Buprenorphine Hydrochloride in a Microemulsion Formulation. J App Pharm Sci, 2016; 6 (10): 159169. 